\title{
Body-PILLAR Vision Obstructions and Lane-Change Crashes
}

\author{
Michael SivaK \\ BRANDON SCHOETTLE \\ MATTHEW P. REED \\ MichaEL J. FlanNagan
}

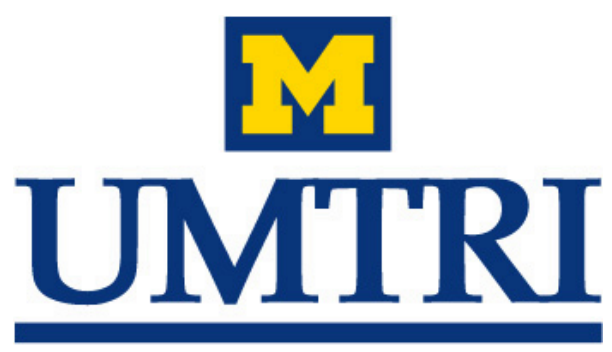

UNIVERSITY OF MICHIGAN

TRANSPORTATION RESEARCH INSTITUTE 


\title{
BODY-PILLAR VISION OBSTRUCTIONS AND LANE-CHANGE CRASHES
}

\author{
Michael Sivak \\ Brandon Schoettle \\ Matthew P. Reed \\ Michael J. Flannagan
}

The University of Michigan

Transportation Research Institute

Ann Arbor, Michigan 48109-2150

U.S.A.

Report No. UMTRI-2006-29

September 2006 
Technical Report Documentation Page

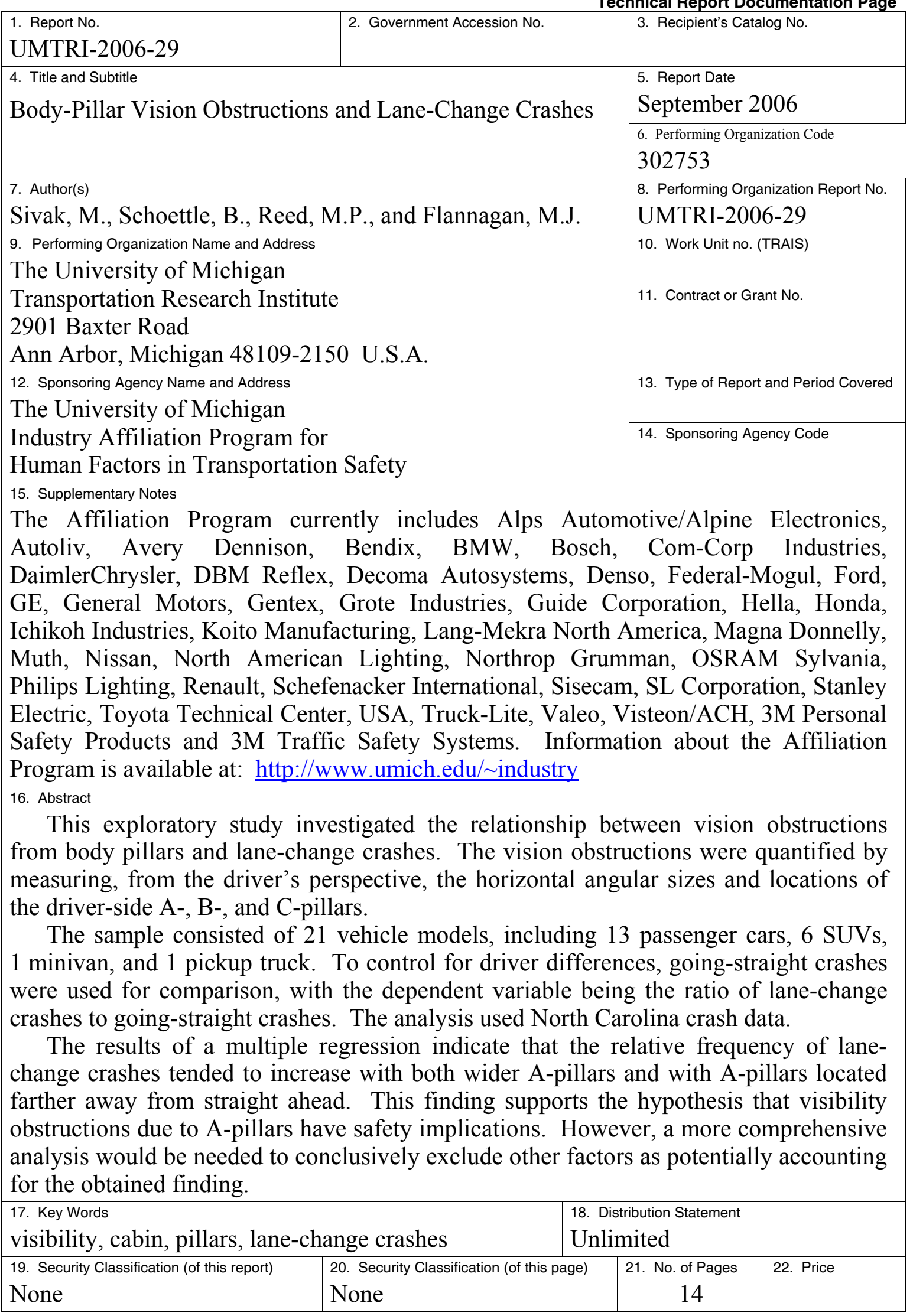




\section{Acknowledgment}

Appreciation is extended to the members of the University of Michigan Industry Affiliation Program for Human Factors in Transportation Safety for support of this research. The current members of the Program are:

\begin{tabular}{ll} 
Alps Automotive/Alpine Electronics & Koito Manufacturing \\
Autoliv & Lang-Mekra North America \\
Avery Dennison & Magna Donnelly \\
Bendix & Muth \\
BMW & Nissan \\
Bosch & North American Lighting \\
Com-Corp Industries & Northrop Grumman \\
DaimlerChrysler & OSRAM Sylvania \\
DBM Reflex & Philips Lighting \\
Decoma Autosystems & Renault \\
Denso & Schefenacker International \\
Federal-Mogul & Sisecam \\
Ford & SL Corporation \\
GE & Stanley Electric \\
General Motors & Toyota Technical Center, USA \\
Gentex & Truck-Lite \\
Grote Industries & Valeo \\
Guide Corporation & Visteon/ACH \\
Hella & $3 \mathrm{M}$ Personal Safety Products \\
Honda & $3 \mathrm{M}$ Traffic Safety Systems \\
Ichikoh Industries & \\
& \\
\hline
\end{tabular}




\section{Contents}

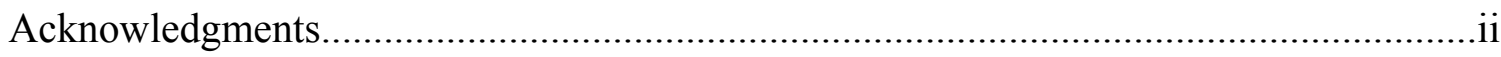

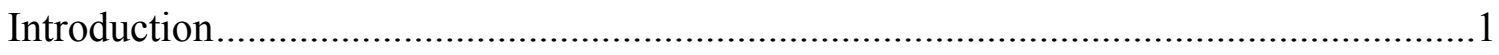

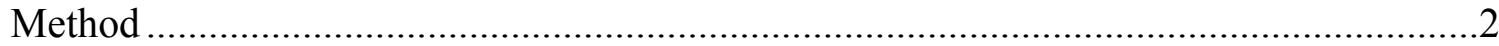

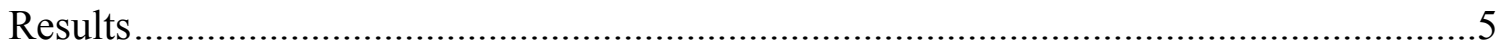

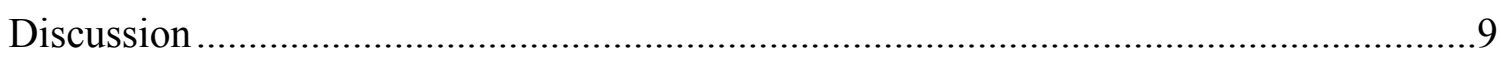

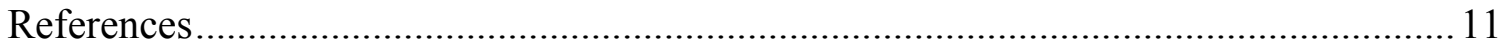




\section{Introduction}

Our previous study in this series examined the difference in the frequency of lanechange crashes between two-door and four-door body styles of the same vehicle models (Sivak, Schoettle, Reed, and Flannagan, 2005). That study found that four-door vehicles are more likely to be involved in lane-change crashes than are two-door vehicles. We postulated that this effect was a consequence of the more critical obstruction of lateral visibility on the four-door models by the more forward location of the B-pillars.

The present study is an extension of the work in Sivak et al. (2005). Specifically, this study investigates the tendency to be involved in lane-change crashes in relation to the locations and angular obstructions of the driver-side A-, B-, and C-pillars for a large set of vehicles.

If the location of the A-pillar were important for lane-change crashes, then one would expect that there would be a significant positive relationship between the horizontal angle from straight ahead to the A-pillar and the likelihood of lane-change crashes. This is the case because a larger angle implies that the pillar obscures an area in an adjacent lane that is longitudinally nearer to the vehicle. Analogously, a negative correlation would be expected for the angle to the B-pillar, because the smaller the angle, the nearer the pillar is to the fore-aft position of the driver. There is no clear prediction concerning the expected direction of the relationship between the location of C-pillars and lane-change crashes.

If the size of the pillars were important for lane-change crashes, then one would expect that there would be a significant positive relationship between the obstruction angles of the pillars themselves and the likelihood of lane-change crashes.

As we discussed in Sivak et al. (2005), a simple comparison of lane-change crashes of different vehicle models would likely be confounded by driver differences. These driver differences, in turn, are likely to influence the amount and type of driving exposure, as well as driving style (including risk taking). Therefore, as in Sivak et al. (2005), we used the frequency of crashes that involve going straight as a control because this type of crash should capture many of the driver differences and not be affected by lateral visibility. 


\section{Method}

\section{Vehicles}

The sample consisted of 21 vehicles, including 13 passenger cars, 6 SUVs, 1 minivan, and 1 pickup truck. The year, make, model, and body style information for each vehicle were verified using the vehicle identification number (VIN) reporting feature ("Vehicle History Report") in CARFAX (2006). The measured vehicles are listed in Table 1.

Although each measured vehicle was of a specific model year, most vehicle models exist for several model years without significant design changes to the body or general structure of the vehicle. To determine the range of applicable model years for each measured vehicle, historical information about the duration of a specific model's design was obtained from Consumer Guide (2006). The applicable model years that were used in this analysis are listed in the last column of Table 1.

\section{Crash database}

We used 1996-2003 North Carolina crash data (UNC, 2005) to compile crash frequencies for the selected vehicles. ${ }^{1}$ This database includes all reportable North Carolina traffic crashes (fatal, injury, and property damage). The VINDICATOR User's Manual (IIHS, 2005) was employed to identify the appropriate series and model codes for each vehicle. These codes combine to form the VINDICATOR variable 254, "make/model," and this variable was used to select the proper combinations of vehicle models, body styles, and model years from within the North Carolina crash database. Crash frequencies were then tabulated for the following crash-related vehicle maneuvers (variable 149): "changing lanes or merging" (vehicle maneuver code: 05), and "going straight ahead" (vehicle maneuver code: 04).

1 The 2004 model year vehicles were introduced in 2003. Therefore, the 2003 crash database includes some 2004 model year vehicles. 
Table 1

Measured vehicles and model years in the crash analysis.

\begin{tabular}{|c|c|c|c|}
\hline Make and model & Body style & $\begin{array}{l}\text { Measured } \\
\text { model year }\end{array}$ & $\begin{array}{l}\text { Model years in } \\
\text { crash analysis }\end{array}$ \\
\hline Buick Regal & 4-door, sedan & 2003 & $1997-2004$ \\
\hline Cadillac Deville & 4-door, sedan & 2004 & $2000-2004$ \\
\hline Chevrolet Impala & 4-door, sedan & 2004 & $2000-2004$ \\
\hline Chevrolet Malibu & 4-door, sedan & 2003 & $1997-2003$ \\
\hline Dodge Caravan SE & 4-door, minivan & 2005 & 2001-2004 \\
\hline Dodge Ram 1500 Quad Cab & 4-door, pickup truck & 2005 & $2002-2004$ \\
\hline Ford Focus & 4-door, sedan & 2001 & $2000-2004$ \\
\hline Ford Taurus & 4-door, sedan & 2001 & $2000-2004$ \\
\hline GMC Envoy & 4-door, SUV & 2004 & $2002-2004$ \\
\hline GMC Yukon & 4-door, SUV & 2005 & $2000-2004$ \\
\hline Honda Civic & 2-door, coupe & 2004 & 2001-2004 \\
\hline Honda CR-V & 4-door, SUV & 2003 & 2002-2004 \\
\hline Jeep Grand Cherokee & 4-door, SUV & 2004 & $1999-2004$ \\
\hline Jeep Liberty & 4-door, SUV & 2002 & 2002-2004 \\
\hline Mazda Protégé 5 & 4-door, wagon & 2003 & $1999-2003$ \\
\hline Mercury Mountaineer & 4-door, SUV & 2002 & 2002-2004 \\
\hline Nissan Altima & 4-door, sedan & 2003 & 2002-2004 \\
\hline Oldsmobile Intrigue & 4-door, sedan & 2002 & $1998-2002$ \\
\hline Saturn SL & 4-door, sedan & 2002 & 1996-2002 \\
\hline Toyota Camry & 4-door, sedan & 2002 & $2002-2004$ \\
\hline Volkswagen Passat & 4-door, sedan & 2002 & $1998-2004$ \\
\hline
\end{tabular}




\section{Vehicle measurements}

Pillar dimensions were recorded as part of a more comprehensive measurement of each vehicle. A FARO Arm coordinate measurement machine was used to digitize points and surfaces on the interior and exterior of the vehicle, including the perimeters of the windows that define the A-, B-, and C-pillar vision obstructions. The locations of the steering wheel and accelerator pedal were measured, and the seat H-point travel path was measured using the SAE J826 manikin (SAE, 1995). Using the steering wheel location and seat-track adjustment range, the 95th-percentile SAE J941 cyclopean eyellipse (SAE, 2002) was located within the vehicle cabin. The cyclopean eyellipse represents the distribution of the midpoint between the drivers' right and left eyes. All vision dimensions in this report were computed in the horizontal plane passing through the centroid of the cyclopean eyellipse. The angular location of the pillar was defined as the angle of the front edge of the pillar (defined by vision obstruction, not by any particular component of the pillar) in plan view relative to the forward, longitudinal axis of the vehicle. The angular size of the pillar was defined as the difference between the angular locations of the front and rear vision tangent points for the pillar.

\section{Variables and analysis}

The dependent variable was the ratio of the frequencies of lane-change crashes to going-straight crashes, calculated separately for each vehicle model. There were six predictor variables: the horizontal obstruction angles for the driver-side A-, B-, and Cpillars (the angles between the front and rear edges of the pillars from the driver's perspective), and the horizontal angles from straight ahead to the front edge of the pillars (again from the driver's perspective).

A backward multiple-regression analysis was used to relate the crash ratios to the amount of visual obstruction created by each of the three pillars on the driver side, and to the locations of each of these pillars within the driver's field of view. 


\section{Results}

\section{Descriptive statistics}

The analyses were based on 1,250 lane-change crashes and 23,796 going-straight crashes. The means and ranges of the dependent and predictor variables are listed in Table 2.

Table 2

Means and ranges of the dependent and predictor variables.

\begin{tabular}{|l|c|c|c|}
\hline \multicolumn{1}{|c|}{ Variable } & Minimum & Mean & Maximum \\
\hline \hline Lane-change/going-straight crashes & .040 & .056 & .077 \\
\hline Size of A-pillar (degrees) & 6.1 & 8.3 & 9.9 \\
\hline Size of B-pillar (degrees) & 9.9 & 16.7 & 20.2 \\
\hline Size of C-pillar (degrees) & 1.6 & 4.4 & 8.9 \\
\hline Angle to A-pillar (degrees) & 22.5 & 24.9 & 28.6 \\
\hline Angle to B-pillar (degrees) & 112.4 & 122.5 & 141.9 \\
\hline Angle to C-pillar (degrees) & 160.1 & 163.7 & 167.4 \\
\hline
\end{tabular}

\section{Predictor variables vs. ratio of lane-change to going-straight crashes}

Using the backward regression method, a significant model emerged $\left(F_{2,18}=4.23\right.$, $p<0.05, r^{2}=.32$, adjusted $\left.r^{2}=.24\right)$. The significant predictor variables were the size of the A-pillar (standardized $\beta=.37$ ) and the angle to the A-pillar (standardized $\beta=.35$ ). The directions of the significant effects were as expected, with both predictor variables being positively related to the crash ratio. Figures 1 and 2 present the scatter plots of each of the two significant predictors vs. the ratio of lane-change to going-straight crashes. 


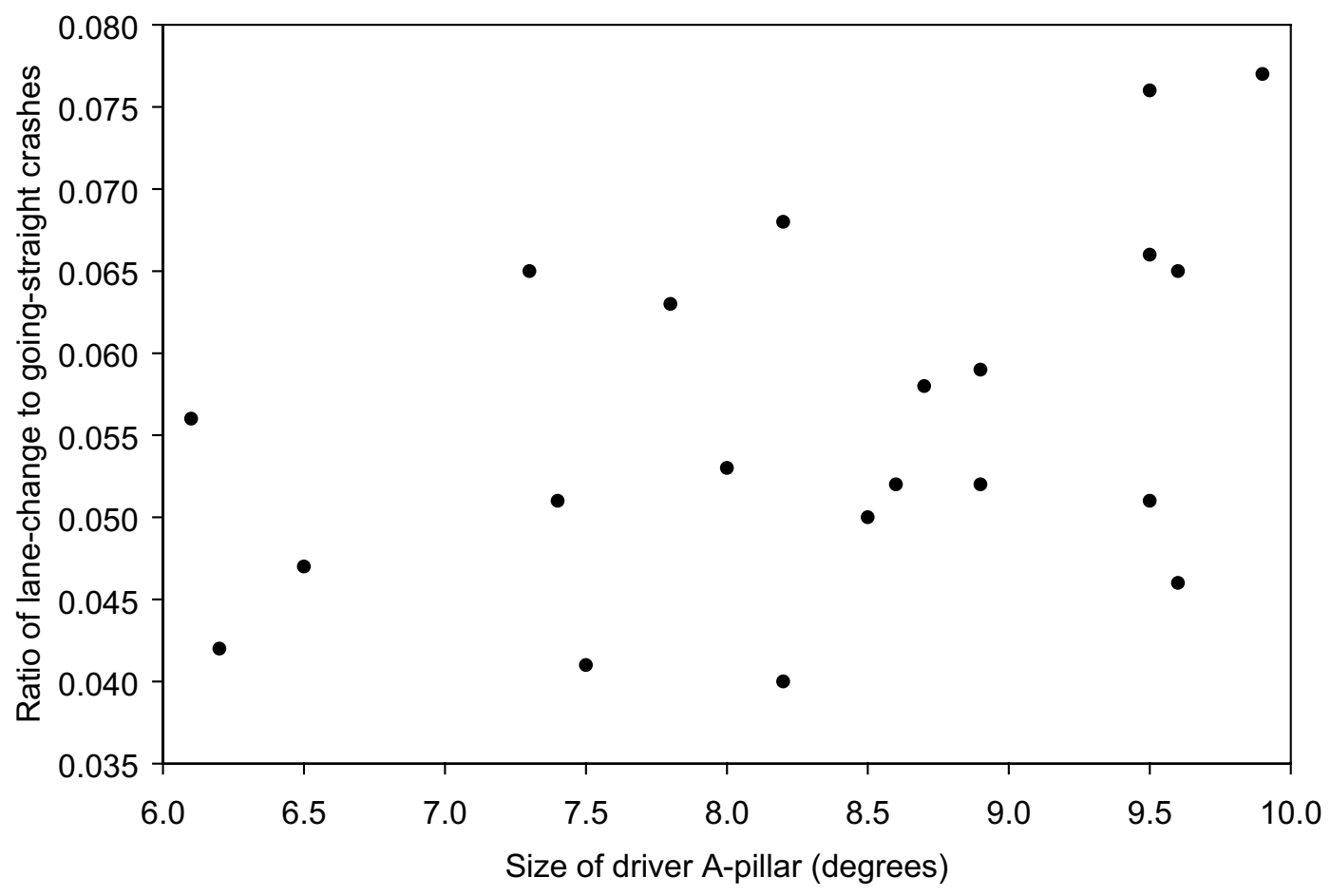

Figure 1. Scatter plot of the size of the A-pillar vs. the ratio of lane-change to goingstraight crashes.

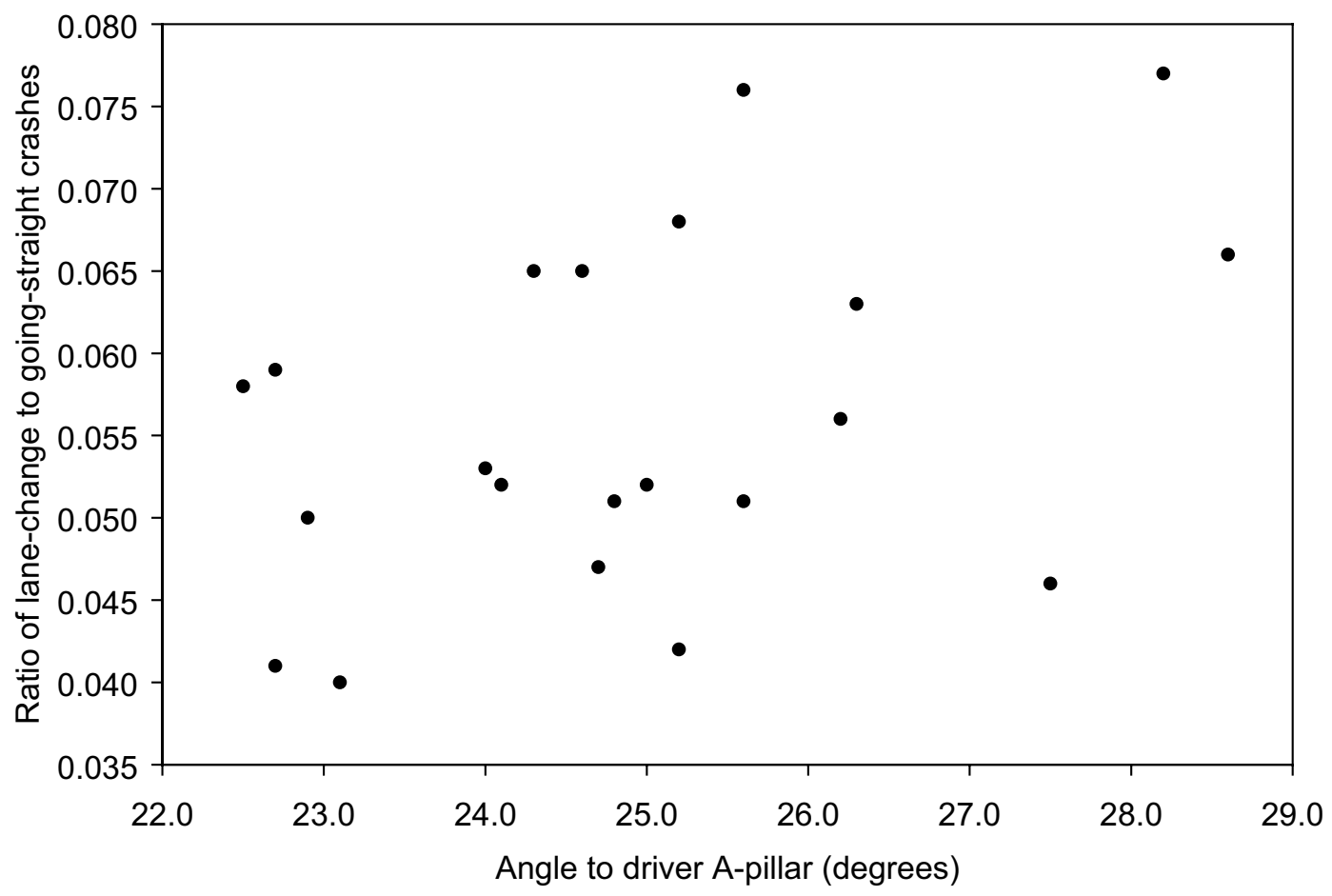

Figure 2. Scatter plot of the location of the A-pillar vs. the ratio of lane-change to goingstraight crashes. 


\section{Interrelationships among the predictor variables}

Pairwise correlations among the predictor variables were examined (see Table 3) to ascertain whether the two significant predictor variables (the size and location of the A-pillar) were highly correlated with the other four predictor variables. As is evident from Table 3, these correlations were only low to moderate. The highest correlation involving the size of the A-pillar was .46 (with the size of the C-pillar); for the location of the A-pillar it was .33 (with the location of the C-pillar). ${ }^{2}$

Table 3

Pearson product-moment correlations among the predictor variables.

\begin{tabular}{|l|c|c|c|c|c|c|}
\hline & $\begin{array}{c}\text { Size of } \\
\text { A-pillar }\end{array}$ & $\begin{array}{c}\text { Size of } \\
\text { B-pillar }\end{array}$ & $\begin{array}{c}\text { Size of } \\
\text { C-pillar }\end{array}$ & $\begin{array}{c}\text { Angle to } \\
\text { A-pillar }\end{array}$ & $\begin{array}{c}\text { Angle to } \\
\text { B-pillar }\end{array}$ & $\begin{array}{c}\text { Angle to } \\
\text { C-pillar }\end{array}$ \\
\hline \hline Size of A-pillar & 1 & -.21 & .46 & .22 & .30 & .30 \\
\hline Size of B-pillar & -.21 & 1 & -.50 & -.32 & -.69 & .00 \\
\hline Size of C-pillar & .46 & -.50 & 1 & .08 & .56 & -.17 \\
\hline Angle to A-pillar & .22 & -.32 & .08 & 1 & .17 & .33 \\
\hline Angle to B-pillar & .30 & -.69 & .56 & .17 & 1 & -.14 \\
\hline Angle to C-pillar & .30 & .00 & -.17 & .33 & -.14 & 1 \\
\hline
\end{tabular}

\section{Vehicle type}

We performed t-tests to evaluate the differences between passenger cars and other vehicles on the significant predictor variables and on the dependent variable. Although passenger cars tended to have larger A-pillars $\left(8.5^{\circ}\right.$ vs. $\left.8.0^{\circ}\right)$, larger angles to A-pillars $\left(25.3^{\circ}\right.$ vs. $\left.24.3^{\circ}\right)$, and greater ratios of lane-change to going-straight crashes (0.058 vs. 0.052), none of these differences was statistically significant. Nevertheless, an additional multiple regression was performed, with the vehicle type added to the list of predictor variables. However, the results were unchanged, with the size of the A-pillar and the angle to the A-pillar being the only significant predictors of the ratio of lane-change to going-straight crashes.

2 Overall, the highest correlation was between the size and location of the B-pillar (-.69), implying that the farther forward a B-pillar was, the larger the pillar tended to be. 
The final set of regression analyses added the following vehicle variables (one at a time, because of high intercorrelations among them) to the original predictor variables: seating reference point (SgRP) height above the accelerator heel point (SAE dimension H30 [SAE, 2001]), SgRP above ground (SAE dimension H5 [SAE, 2001]), height of door line above ground, and top of door to SgRP. Again, the size of the A-pillar and the angle to the A-pillar remained the only significant predictors of the ratio of lane-change to going-straight crashes. 


\section{Discussion}

\section{Main finding}

Lane-change crashes could be influenced by visibility restrictions of an adjacent lane to the front, side, or rear. Adjacent-lane visibility to the front, and thus A-pillar obstructions, are of potential importance in situations where the vehicle in question is closing in on another vehicle in the intended lane of travel. Analogously, adjacent-lane visibility to the rear, and thus C-pillar obstructions, are of potential relevance in situations where a vehicle in the intended lane of travel is closing in on the vehicle in question. Visibility to the side, and thus B-pillar obstructions, are conceptually relevant to both of these scenarios.

The results of the present study are supportive of the influence of A-pillars on lane-change crashes. Specifically, we found that lane-change crashes tended to increase with both wider A-pillars and with A-pillars located farther away from straight ahead.

\section{Comparison to the previous study}

In the previous study (Sivak et al., 2005), we found four-door styles to be more likely to be involved in lane-change crashes than two-door styles. We suggested that the more forward location of the B-pillars on four-door models likely contributed to this effect.

In the present study, the location of the B-pillars was not a significant predictor of lane-change crashes. Although the reason for the difference is not entirely clear, it is possible that the variation in the locations of the B-pillars in Sivak at al. (2005) was greater than in the present study. This is a plausible explanation, because in the previous study we attempted to maximize the differences in the B-pillar locations by comparing four- and two-door styles of the same model vehicles. (However, we did not quantify the locations of B-pillars in that study.) In contrast, out of the 21 vehicles in the present study, there was only one two-door vehicle. The remaining vehicles were either fourdoor passenger cars, four-door SUVs, a four-door minivan, or a four-door pickup truck. 


\section{Limitations of the study}

Controlling for driver differences. The dependent variable was the ratio of lanechange to going-straight crashes. This ratio was used in an attempt to control for driver differences among different model vehicles. The underlying rationale was that driver differences (in terms of exposure and driving style) equally affect both lane-change and going-straight crashes, but are unaffected by pillar obstructions. Both of these assumptions are likely to be violated to some degree.

Inferences from multiple regression. Multiple regression simultaneously considers the influence of all predictor variables on the dependent variable. However, no causation can be directly inferred from the results of multiple regression. This is the case because the significant predictor variables from a regression could be related to true causative variables that were not entered into the regression. Consequently, the results of any multiple regression analysis, including the present one, need to be interpreted with caution.

\section{Conclusions}

The present results suggest that vision obstructions from A-pillars might play a role in lane-change crashes. This inference should be considered tentative, pending a more comprehensive analysis that would evaluate whether other factors could account for the observed pattern of results. 


\section{References}

CARFAX (2006). Vehicle history report. Retrieved July 19, 2006, from:

http://www.carfax.com.

Consumer Guide. (2006). Automotive. Retrieved July 19, 2006 from:

http://auto.consumerguide.com.

IIHS [Insurance Institute for Highway Safety]. 2005. VINDICATOR user's manual. Arlington, VA: Highway Loss Data Institute of the Insurance Institute for Highway Safety.

SAE [Society of Automotive Engineers]. (1995). Devices for use in defining and measuring seating accommodation (SAE Standard J826). Warrendale, PA: Society of Automotive Engineers.

SAE [Society of Automotive Engineers]. (2001). Motor vehicle dimensions (SAE Recommended Practice J1100). Warrendale, PA: Society of Automotive Engineers.

SAE [Society of Automotive Engineers]. (2002). Motor vehicle drivers' eye locations (SAE Recommended Practice J941). Warrendale, PA: Society of Automotive Engineers.

UNC [University of North Carolina]. (2005). North Carolina Crash Data, 2003. Chapel Hill, NC: University of North Carolina Highway Safety Research Center. 